\title{
THE MECHANISM OF CROSSING-OVER. IV
}

\author{
HERMANN J. MULLER
}

Colunibta Untverstty

THE "map" of the first chromosome, based on these experiments, is shown below:

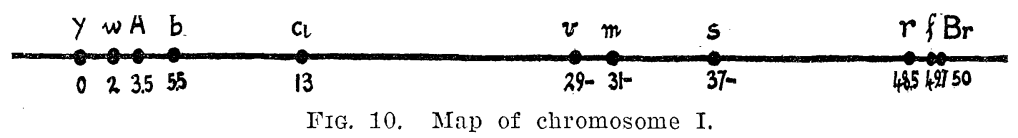

The figures represent the distances of the factors from yellow, the first one in the line, and are calculated merely by adding together the intermediate distances. This map gives almost exactly the same proportionate distances between the different loci as does that obtained by combining the results of linkage experiments performed by other workers, in which usually the inheritance of only two or three factors was followed at one time. Each set of ratios, therefore, confirms the accuracy of the other. The absolute distances in the present map are, however, somewhat shorter, being $6 / 7$ the length of those in the composite map. This was caused mainly by the comparatively large number of non-cross-overs produced by a few females; in the rest, the crossing-over frequencies were about normal. It may, therefore, be concluded that chromosomes which differ in regard to eleven pairs of factors behave in the same way, so far as crossing-over is concerned, as those which are alike except for two factors. This is contrary to a suggestion made by Punnett. Moreover, the fact that chromosomes differing in so many factors behave normally is here especially noteworthy, because 11 of the 12 recessive factors were in the same chromosome.

The results of the experiments with the second chromosome may now be tabulated. 462 offspring of females 
heterozygous for the ten mutant factors used in this group have been recorded.: The table only gives the result with respect to nine characters, however, as are wing was not followed in all of the experiments. (The data given later as to its position have, accordingly, not been calculated from quite as large a count of flies as have the data for the other factors.)

Classification of Factor Combinations Transmitted by Females

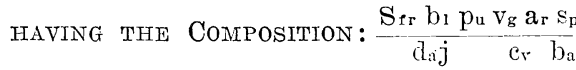

\begin{tabular}{l|l|l|l}
\hline \hline & Streak & Not Streak & Total \\
\hline
\end{tabular}

Non-cross-overs

\begin{tabular}{l|ll|ll|l|l}
\hline & Sbpvas & 68 & djcb & 82 & 150 \\
\hline
\end{tabular}

Between

Single Cross-overs

\begin{tabular}{|c|c|c|c|c|c|}
\hline $\mathbf{S}_{\mathrm{tr}}$ and $\mathrm{d}_{\mathrm{a}} \ldots \ldots \ldots \ldots$ & $S d j \quad c b$ & 11 & $b p v s$ & 15 & 26 \\
\hline$d_{a}$ and $b_{1} \ldots \ldots \ldots \ldots \ldots \ldots$ & $S j$ & 24 & $d b p v s$ & 19 & 43 \\
\hline$b_{1}$ and $j \ldots \ldots \ldots \ldots \ldots$ & $S b j$ & $1 ?$ & $d p v s$ & 0 & 1 ? \\
\hline $\mathrm{j}$ and $\mathrm{p}_{\mathrm{u}} \ldots \ldots \ldots$ & $S b \quad c b$ & 3 & $d j p o s$ & 6 & 9 \\
\hline$p_{u}$ and $v_{g} \ldots \ldots \ldots \ldots \ldots$ & $S b p c b$ & 14 & $d j v s$ & 20 & 34 \\
\hline$v_{\mathrm{g}}$ and $c_{v} \ldots \ldots \ldots \ldots$ & $S b p v c b$ & 10 & $d j \quad s$ & 11 & 21 \\
\hline$c_{v}$ and $s_{p} \ldots \ldots \ldots \ldots \ldots \ldots$ & $S \quad b p v \quad b$ & 51 & $d j$ & 50 & 101 \\
\hline$s_{p}$ and $b_{a} \ldots \ldots \ldots \ldots \ldots$ & $S b p v s b$ & 0 & $d j \quad c$ & 0 & 0 \\
\hline
\end{tabular}

Double Cross-overs

\begin{tabular}{|c|c|c|c|c|c|}
\hline$S_{\operatorname{tr}}$ and $d_{\imath} ; p_{u}$ and $v_{g} \ldots \ldots \ldots$ & $S d j$ & 2 & $b p c b_{a}$ & 1 & 3 \\
\hline Str and $d_{n} ; v_{g}$ and $c_{v} \ldots \ldots$ & $S d j$ & 1 & $b p v c b_{a}$ & 0 & 1 \\
\hline$S_{\text {tr }}$ and $d_{n} ; c_{v}$ and $s_{p} \ldots$ & $S d j$ & 5 & $b p v b_{a}$ & 8 & 13 \\
\hline$d_{a}$ and $b_{l} ; j$ and $p_{u} \ldots \ldots \ldots$ & $S j p v s$ & 1 & $d b \quad c b_{a}$ & 0 & 1 \\
\hline$d_{\mathrm{a}}$ and $b_{l} ; p_{u}$ and $v_{g} \ldots \ldots$ & $S j v s$ & 5 & $d b p c b_{a}$ & 5 & 10 \\
\hline $\mathrm{d}_{\mathrm{a}}$ and $\mathrm{b}_{1} ; \mathrm{v}_{\mathrm{g}}$ and $\mathrm{c}_{v} \ldots \ldots$ & $S j$ & 5 & $d b p v c b_{a}$ & 1 & 6 \\
\hline$d_{a}$ and $b_{1} ; c_{v}$ and $s_{p} \ldots \ldots \ldots$ & $S j \quad c s$ & 5 & $d b p v \quad b_{a}$ & 8 & 13 \\
\hline $\mathrm{j}$ and $\mathrm{p}_{\mathrm{u}} ; \mathrm{p}_{\mathrm{u}}$ and $\mathrm{v}_{\mathrm{g}} \ldots \ldots$ & $S b v s$ & 1 & $d j p c b_{a}$ & 1 & 2 \\
\hline $\mathrm{j}$ and $\mathrm{p}_{\mathrm{u}} ; \mathrm{v}_{\mathrm{g}}$ and $\mathrm{c}_{\mathrm{v}} \ldots \ldots$ & $\begin{array}{lll}S & b & s\end{array}$ & 0 & $d j p v c b_{a}$ & 1 & 1 \\
\hline $\mathrm{j}$ and $\mathrm{p}_{\mathrm{u}} ; \mathrm{c}_{\mathrm{v}}$ and $\mathrm{s}_{\mathrm{p}} \ldots \ldots \ldots$ & $S \quad b \quad c s$ & 7 & $d j p v b_{a}$ & 1 & 8 \\
\hline$p_{u}$ and $v_{g} ; v_{g}$ and $c_{v} \ldots \ldots \ldots$ & $S \quad b p \quad s$ & 0 & $d j v c b_{a}$ & 2 & 2 \\
\hline$p_{u}$ and $v_{s s} ; c_{v}$ and $s_{p} \ldots \ldots \ldots$ & $b p c s$ & 3 & $d j v b_{a}$ & 3 & 6 \\
\hline$v_{g}$ and $c_{V} ; c_{v}$ and $s_{p} \ldots \ldots \ldots$ & $S$ bpvcs & 2 & $d j \quad b_{a}$ & 1 & 3 \\
\hline
\end{tabular}

Triple Cross-overs

\begin{tabular}{|c|c|c|c|}
\hline $\begin{array}{l}S_{t r} \text { and } d_{a} ; d_{a} \text { and } b_{l} ; c_{v} \text { and } s_{p} . \\
S_{t r} \text { and } d_{a} ; j \text { and } p_{u} ; c_{v} \text { and } s_{p} \ldots \\
d_{\mathrm{a}} \text { and } b_{1} ; j \text { and } p_{u} ; p_{u} \text { and } v_{g} \ldots \\
d_{\mathrm{a}} \text { and } b_{l} ; j \text { and } p_{u} ; c_{v} \text { and } s_{p} \ldots \\
d_{a} \text { and } b_{1} ; p_{u} \text { and } v_{s} ; c_{v} \text { and } s_{p} . . \\
j \text { and } p_{u} ; p_{u} \text { and } v_{s} ; c_{v} \text { and } s_{p} . .\end{array}$ & 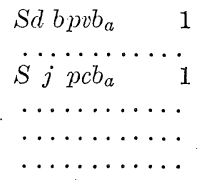 & $\begin{array}{llll}\cdots & \cdots & \cdots & \\
b & c s & 1 \\
\cdots & \cdots & \cdots & \\
d b & c s & 1 \\
d b & p & c s & 1 \\
d j p & c s & 1\end{array}$ & $\begin{array}{l}\cdots \\
\cdots \\
\cdots \\
\cdots \\
\cdots \\
\cdots\end{array}$ \\
\hline
\end{tabular}


Total Single, Double, and Triple Crossing-over

\begin{tabular}{|c|c|c|}
\hline Between & $\begin{array}{l}\text { Observed } \\
\text { Number }\end{array}$ & $\begin{array}{l}\text { Per Cent. of } \\
\text { Crossing-over }\end{array}$ \\
\hline Ser and d & . 45 & 9.7 \\
\hline$d_{a}$ and $b_{1}$ & 77 & 16.7 \\
\hline$b_{1}$ and $j$ & $1 ?$ & $0.2 ?$ \\
\hline$j$ and $p_{u}$ & 25 & 5.4 \\
\hline$p_{u}$ and $v_{g}$ & 59 & 12.8 \\
\hline $\mathrm{vg}_{\mathrm{g}}$ and $\mathrm{c}_{\mathrm{v}}$ & 34 & 7.1 \\
\hline$c_{v}$ and $s_{p}$ & . 150 & 32.5 \\
\hline$s_{p}$ and $b_{a}$ & . 0 & 0.0 \\
\hline
\end{tabular}

In the case of this chromosome, too, the law of linear linkage is graphically illustrated by the characteristic "sectional" mode of interchange between the groups. The non-cross-overs here constitute only 32.5 per cent. of the population, whereas the single cross-overs make up 51.1 per cent., the double cross-overs 15.2 per cent., and the triple cross-overs 1.3 per cent. In making a map of this chromosome, the chances of error are greater than in the preceding case, since not so many flies have been obtained. Nevertheless, the values correspond very closely with estimates of the results obtained in other work, although figures exactly representing the sum total of other work are not just now available for comparison.

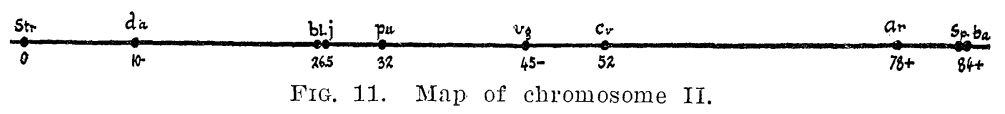

Let us now construct a curve showing the frequency with which, in the experiment with the first chromosome, points various distances apart showed coincidence of crossing-over. Suppose that in this curve the horizontal line represents the distance apart of the two coincident cross-overs, and the vertical line the per cent. of cases in which double crossings-over at such distances occur. For example, if it were known that double crossing-over for a distance anywhere between 15 and 16 units occurred in .2 per cent. of all cases the height of the curve above the figures 15 and 16 would be made .2 vertical units. Now, each case of double crossing-over that actually happens 
among the 712 flies obtained for group I must represent $\frac{1}{712}$, or .14 per cent., of all the cases. If, then, a crossingover is found to occur somewhere between $c_{1}$ and $\mathrm{v}$, and one occurs coincidentally between s and r, the two points of crossing-over may have been as far apart as $c_{1}$ and $r$ (36), or as close together as $\mathrm{v}$ and $\mathrm{s}$ (8), or at any intermediate distance. Therefore we have no right to make this case stand, in the curve, for a coincidence that happened at a particular distance (say 10-11) and to raise the ordinates for this particular distance by .14 units. Each distance between 8 and 36 is consequently given partial credit in our curve for the occurrence of this coincidence, and so each of the 28 ordinates between 8 and 36 is raised to an average height of $\frac{.14}{28}=.005$ approximately. All the other cases are treated in a similar way, and thus the curve shown by the heavy line in Fig. 12 is obtained.

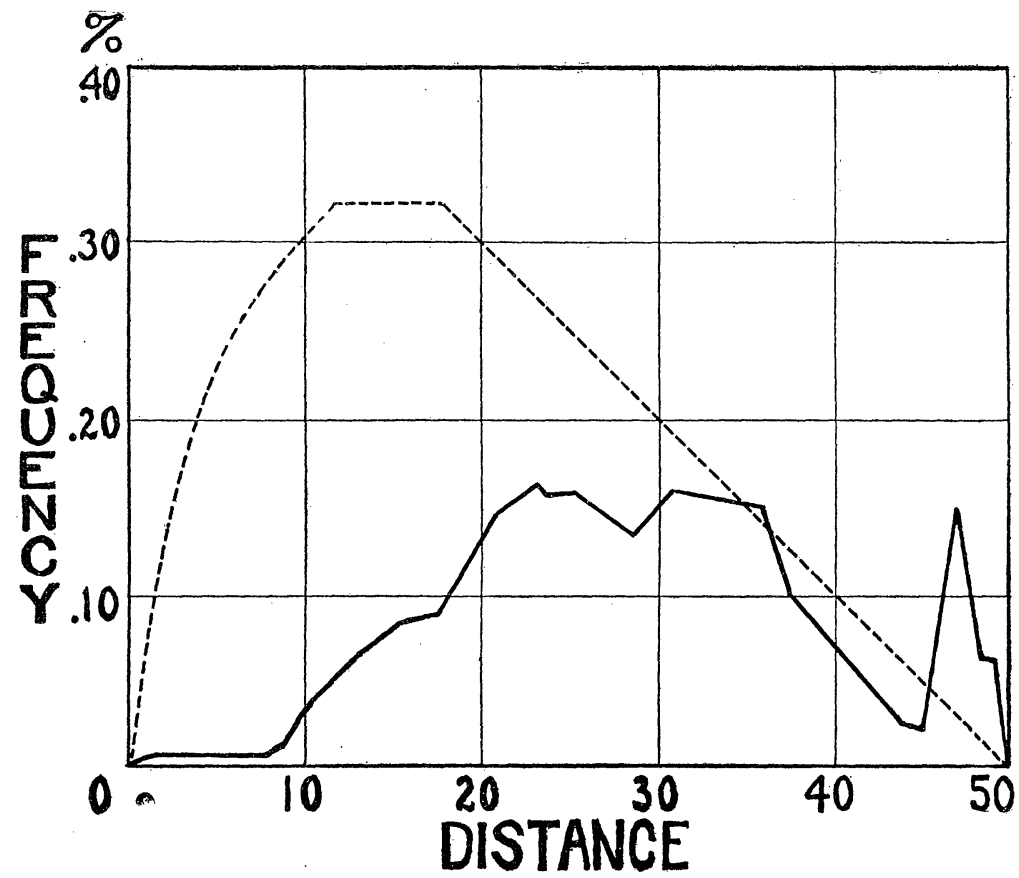

FIG. 12. Curve showing the observed frequency of double crossing-over in chromosome $I$, for points various distances apart. The dotted line shows the frequency expected on pure chance. 
But although these ordinates are, on the average, raised by this amount, each one is not raised equally, for there is less chance that double cross-overs should have the most extreme possible values than medium values. The total addition of .14 units to the curve should hence be distributed among the different possible ordinates according to the relative probabilities that the two points of crossingover should have been the distance apart represented by these respective ordinates. These various probabilities for the different ordinates, in the case of any specific double cross-over, may be represented in the form of a curve, and the main curve of double cross-over frequency shown in figure 12 is thus really a composite in which these individual curves for each double cross-over have been added together. We may now consider the way in which the individual curves of probability are calculated.

Let us take the case of the double cross-over that occurred between $c_{1}$ and $v$ and coincidently between $s$ and $r$. We have already calculated that the distance between the two points of crossing-over must be somewhere between 8 units and 36 units (see second paragraph above). The curve for this individual double cross-over will therefore start at 8 on the abscissa and continue to 36 . What height shall it have along the ordinates between these points? Let the region $c_{1}-\mathrm{v}$ be divided into 8 equal parts -abedefgh-of two units each, as shown below.

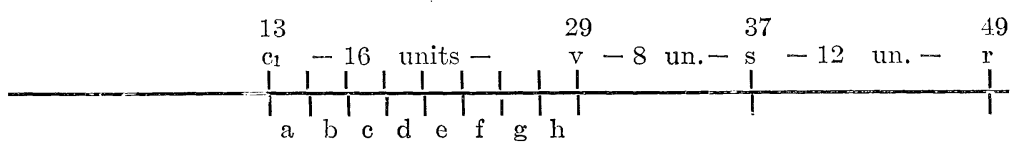

It will be seen that a double cross-over of 8 to 10 units length (i.e., having 8 to 10 units between its two points of crossing-over) which passes between the factors $\mathrm{c}_{1}$ and $\mathrm{v}$, must go between them in the region h, if its other point of crossing-over is to be between $\mathrm{s}$ and $\mathrm{r}$. However, any double cross-over of 10 to 12 units length which passes through either $\mathrm{g}$ or $\mathrm{h}$ will also pass between $\mathrm{s}$ and $\mathrm{r}$, and so there is twice as much chance for double cross-overs of 
this length to occur as for those 8 to 10 units long. Similarly, those 12-14 units long may be three times as numerous, for they may pass through $\mathrm{f}, \mathrm{g}$, or $\mathrm{h}$, and so with each increment of length, up to 20 , there will be an equal additional amount of chance for a double cross-over of that length (passing through the required sections, $c_{1}-v$ and $\mathrm{s}-\mathrm{r}$ ) to occur. Thus our curve of probability rises in regular steps from 8 to 20 ; if we could have divided the distance $c_{1}-\mathrm{v}$ into an infinite number of parts, instead of into 8 , these steps would each be infinitely small, and so we should have a straight line rising from 8 to 20 .

Beyond this point the rise in probability ceases; a double cross-over between 22 and 24 units long has no more chance of happening than one of 20-22 units. Reference to the figure will show that a double cross-over of 20-22 units passing through any of the regions from $\mathrm{c}$ through $h$ will separate $s$ from $r$ and thus fulfill the requirements, but a double cross-over 22-2t units long, while it has the additional alternative of passing through $b$, can not pass through $h$ without its second point of crossing-over falling to the right of section s-r. Similarly, one 24-26 long may not pass through g or h, though it may pass through any region from a to f; double crossovers of all these lengths therefore have the same chance of occurring, and our curve along the corresponding ordinates would hence be a horizontal line.

Double cross-overs longer than this would have less and less chance of occurring; one 26-28 long could only pass. through regions a - e, one 28-30 only through a $-d$, and so the curve falls again in a straight line to the zero level at 36 .

The same rules can be shown to apply to all cases: the curve starts at a place on the abscissa representing the distance apart of the innermost factors involved (in the above case this distance was $\mathrm{v}-\mathrm{s},=8$ ); it rises in a straight line for a distance equal to the length of the smaller section involved (above, this was the distance $\mathrm{s}-\mathrm{r},=12$, so that the line rose to point $8+12,=20)$; 
it then proceeds horizontally until a distance from the starting point of the curve equal to the length of the longer section has been passed (above, this was the section. $\mathrm{c}_{1}-\mathrm{v},=16$; thus the line proceeded on a level to point $\left.8+16=24^{6}\right)$; then it falls in a straight line to a point on the abscissa representing the distance between the outermost factors involved (above, the distance is $c_{1}-r,=36$ ). The height to which the curve rose is determined by the fact that its area (the sum of all the ordinates) must have a value representing the per cent. of total cases in which such a double cross-over occurred (above, each double cross-over must have a curve with an area $=.14$, since each fly was .14 per cent. of the total count).

It will be noted that for each individual curve the probability is calculated on a basis of pure chance, no account being taken of possible interference, which, if present, would tend to make the longer distances more likely than the shorter, and so to raise the right end of the curve at the expense of the left. In other words, each individual curve represents the frequency with which double crossovers of different lengths would happen within the particular regions dealt with (in our case above, regions $c_{1}-\mathrm{v}$ and $s-r)$, if there were no interference and they had a purely chance distribution, within these regions. The composite curve thus errs rather by showing too little effect of interference than too much. All interference which it does show - that is, all deviation between it and a curve representing an entirely random distribution of double cross-overs-must then be due solely to the way in which the double cross-overs were found to be distributed among the various regions, as no assumption of interference was made in calculating out the curve for each double cross-over.

The curve representing the proportion of double crossovers of different lengths which would have been found on an entirely random distribution (no interference) is

6 The discrepancy between this figure (24) and that (26) found by the method of trial used above would disappear if the region $c_{1}-v$ had been divided infinitely instead of only into eight parts. 
shown by the dotted line. To make comparison with the other curve legitimate, it had to be constructed by the same method,-namely, by making a composite of individual curves, each of which represented the probabilities for a certain type of double cross-over-only, instead of using the observed numbers of double cross-overs of the different types, in construeting it, it was necessary to use the numbers of double cross-overs of the different types that would have been observed if there had been no interference. (This curve hence represents the results of a chance distribution both among and within the various regions.) In the case of each type of double cross-over, the way to find the per cent. of individuals showing it that would be produced if there were no interference, is to multiply the total per cent. of crossing-over in the first region by the per cent. in the second region, as explained in section 4a. (Thus, the per cent. of double cross-overs passing between $\mathrm{A}$ and $\mathrm{B}$ and between $\mathrm{C}$ and $\mathrm{D}$ equals per cent. of cross-overs between A and B times per cent. of cross-overs between $\mathrm{C}$ and D.) This per cent., then multiplied by the total number of individuals counted, gives the number of such double cross-over's theoretically to be expected in the absence of interference. When such calcu. lations for each different possible kind of double crossover have been made, and the individual curve for each then made, the latter may be combined to form a composite curve like the curve shown by the dotted line.

The end desired is of course to compare the dotted and the heavy-lined curves and see what proportion of the double cross-overs various distances apart, that were expected on pure chance, actually occurred. Therefore a new curve (Fig. 13) may be made, representing this relative coincidence, $i$. e., the per cent. which each frequency on the observed curve formed of each frequency on the expected curve (see sect. IVa). This curve consequently shows the rise or fall of the index with which we are already familiar, and which we have called simply "coincidence."

Owing to the fact that not very large figures have so far 
been obtained, we must be cautious about accepting the exact values shown in the curve of coincidence; this applies not so much to the main portion of the curve as to the right-hand end (shown in dotted lines), for in the case of very long double cross-overs, very few kinds are even theoretically possible, compared to the number of different

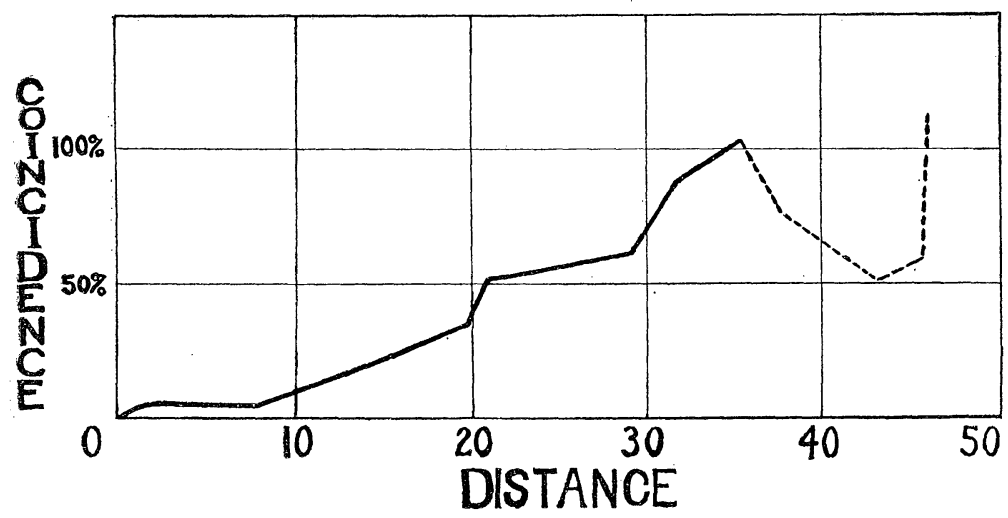

FIG. 13. Curve of coincidence for chromosome $I, i$. e., the ratio of observed double crossing-over for points in chromosome I various distances apart to double crossing-over expected on a chance basis.

positions in which short double cross-overs of a given length may be found. Accordingly, the marked fall, followed by great rise at the very end of the first curve has no true significance.

Certain points may be seen to stand out plainly, however. It is clearly evident that interference is great for short distances $-i$. e., that relative coincidence is low; as distance increases the coincidence rises, at first, quickly, but beyond a certain point the rise ceases.

There is no indication of a usual length of loop of less than half the length of the chromosome, as cytological observations on strepsinema stages would suggest, and as would therefore be expected on the view that crossing-over occurs at that stage. The fall seen near the right hand end is entirely unreliable, as has been explained. But, even if taken at its face value, the drop at this point can have no significance for the question at issue, for a fall due to the loop would have to be as long as the whole pre- 
vious rise. In addition, the curve should, on this explanation, rise high above the 100 per cent. level at its modal point, whereas it is evident that, so far as the significant figures go, it does not rise much above 100 per cent. at any point. It would be premature, however, to generalize further on these results.

The curve for group II will not be presented until greater numbers of flies have been recorded. It may be stated, however, that this curve too shows the phenomenon of interference, although, since the factors are not so close together, the crossing-over for rather small distances cannot so well be followed:

The great variability possible in the distance between two points of crossing-over is shown not only in the above curves, but may be graphically illustrated from a single case. This fly was the triple cross-over in the first chromosome, which has already been mentioned. Its mother was one of the tested females of the count, whose composition proved to have been $\frac{\mathrm{ywAbvmsrf}}{\mathrm{B}_{\mathrm{r}}}$, and it itself was a male with the factors $\mathrm{yr}_{\mathrm{r}}$. Crossing-over, therefore, must have taken place between $\mathrm{y}$ and $\mathrm{w}, \mathrm{s}$ and $\mathrm{r}$, and $\mathrm{r}$ and $\mathrm{f}$. The minimum possible distance between the first two points of crossing-over is 42 , the maximum distance between the second two is 14. The latter is the smallest distance ever observed between two points of crossing-over. It may here be mentioned that it will be of great interest, when more extensive figures are obtained, to see whether in the second chromosome the same coincidence holds between crossings-over on opposite sides of the middle point as between crossings-over an equal distance apart, but on the same side. The bend of the chromosomes in the middle, or some other structural difference here due to the attachment of the spindle fiber at this point, might cause the results to be different in the above two cases.

Incidentally, the results demonstrate another point, lying in a somewhat different field of genetics. By following the method of keeping stocks constantly in heter- 
ozygous condition, twenty-two factors have been continually outcrossed, in each successive generation, to their allelomorphs. Yet after about seventy-five generations of outcrossing, these characters do not show the slightest contamination. The experiment therefore forms an extensive test and verification of the "purity of Mendelian segregation."' Castle has, however, raised the point that in determining whether character's change, we should not be content with casual inspection. One of the characters in the above experiment-dachs legs-lends itself readily to quantitative work, since one of its main features is a shortening of the tarsus and metatarsus. Measurements of the leg's of about a dozen of these dachs flies, derived from the stock which had been subjected to continual outcrossing, were therefore made, as well as measurements of the legs of some dachs flies derived from a stock which had been kept pure; the values for normal flies were determined also. At the same time the thorax length of the flies was observed, in order that any difference in leg length due merely to variation in the size of the whole animal might be allowed for. The results for each individual are shown in the following table. Measurements are given in eyepiece micrometer divisions, each of which represented $.026 \mathrm{~mm}$.

In order to discover whether the character had become more variable as a result of outcrossing, the standard deviation of the ratios of foot to thorax, in the two stocks of dachs, was calculated from the above data. In the outcrossed stock the standard deviation was found to be .036 , and in the original stock .035 ; that is, so far as these results can show, the variability of dachs after outcrossing has remained just the same. However this may be, the fact remains that the character, after being subjected to such long-continued outcrossing, had not approached one whit nearer to the type of its allelomorph. The slight difference in the other direction observed between it and the original mutant stock is of no significance, since just about as great differences in thorax length occurred between the 
two stocks, but in opposite directions in the two sexes. The judgment based upon measurements accordingly confirms the judgments based upon inspection.

Females

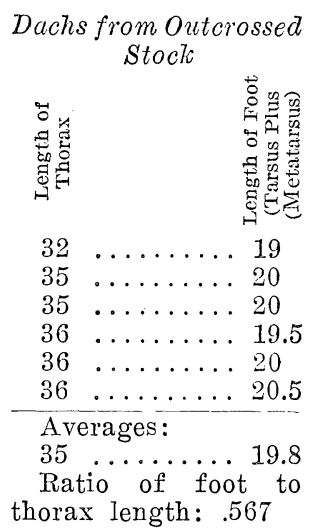

Dachs from Uncrossed

Wild Flies

Stock

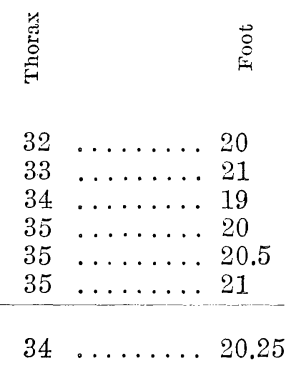

.596

$\begin{array}{llll}41 & \ldots \ldots \ldots & 31 . \\ 42 & \ldots \ldots \ldots & 31\end{array}$

$42 \ldots \ldots \ldots .31$

$42 \ldots \ldots \ldots 31$

$43 \ldots \ldots \ldots 32$

$43 \ldots \ldots 33$

$44 \ldots \ldots \ldots 34$

$42.4 \quad \ldots \ldots \ldots 31.9$
.752

Males

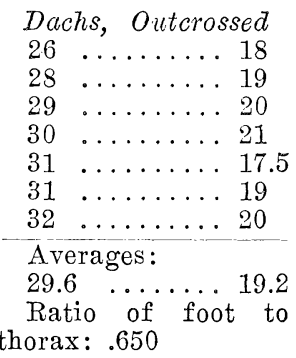

Dachs, Uncrossed $28.5 \ldots \ldots \ldots 17.5$

$29 \ldots \ldots \ldots$

$29 \ldots \ldots \ldots$

$30 \ldots \ldots \ldots 19$

$32 \ldots \ldots \ldots 22$

$\begin{array}{llll}32 & \ldots \ldots \ldots & \ldots & \ldots \\ 33.5\end{array}$

$33.5 \quad \ldots \ldots 23$

$30.6 \quad \ldots \ldots 20.7$

.677

Wild

\begin{tabular}{ccc}
26 & $\ldots \ldots \ldots \ldots$ & 24 \\
29 & $\ldots \ldots \ldots \ldots$ & 26 \\
29 & $\ldots \ldots \ldots \ldots$ & 26 \\
32 & $\ldots \ldots \ldots \ldots$ & 28 \\
33 & $\ldots \ldots \ldots \ldots$ & 29 \\
37 & $\ldots \ldots \ldots$ & 32 \\
\hline 31 & $\ldots \ldots \ldots$ & 27.5 \\
& \\
&
\end{tabular}

\section{Summary}

1. Recent results complete the parallelism between factor groups and chromosomes in Drosophila. This strengthens the evidence that separation of linked factors is due to an interchange between chromosomes.

2. The chief gaps in the information regarding the total frequency of interchange in the different groups have been filled, and it is found that the usual total frequencies of separation correspond to the lengths of the chromosomes. This constitutes specific evidence that crossing-over is the method of interchange between the chromosomes, and that 
the frequency of crossing-over between factors is determined by their distance apart in the chromosome. It supplements the other evidence for these conclusions that had previously been found by Sturtevant in the linear manner of linkage of the factors.

3. It seems uncertain whether crossing-over occurs in the strepsinema stag'e, as concluded by Janssens, or earlier in synapsis. The cytological evidence at present at hand would seem insufficient to settle this point. Possible tests for various alternative mechanisms of crossing-over are proposed.

4. In order to study the nature of crossing-over by means of "interference," stocks were made up that differed in regard to many factors. Females heterozygous for 22 pairs of factors were thus obtained, and a special method was devised for testing their output. Other special methods for obtaining multiple stocks, and for eliminating discrepancies due to differential viability, have also been presented.

5. The results have been arranged in the form of a curve showing the amount of interference for various distances. The results thus far obtained confirm those obtained by less exact methods, and also give evidence that interference decreases gradually with distance from a point of crossing-over; this, taken together with certain evidence from non-disjunction, lends some probability to the view that crossing-over occurs at an early stage in synapsis.

6. A case of crossing-over in an embryonic cell of a male is reported.

7. Incidentally, the experiments have afforded an extensive test of Castle's assumption of contamination of factors by their allelomorphs. Outcrossing in each generation for 75 generations has failed to change any of the factors.

The author is deeply indebted to Professor Morgan, and wishes also to convey his appreciation of the active cooperation so often rendered him by E. R. Altenburg and 
A. H. Sturtevant, who, moreover, on several occasions helped to tide the stocks over critical periods during which it was not possible for the author to carry on the work. Thanks are also due to C. B. Bridges, for supplying several multiple stocks as well as for the use of a number of mutants which he had already located but an account of which he has not yet published.

\section{BIBLIOGRAPHY}

1. Bridges, C. B. 1913. Non-disjunction of the Sex Chromosomes of Drosophila. Jour. Exper. Zool., XV.

2. Bridges, C. B. 1914. Direct Proof through Non-disjunction, etc. Science.

3. Hoge, M. A. 1914. Another Gene in the Fourth Chromosome of Drosophila. AM. NAT.

4. Janssens, F. A. 1909. La Theorie de La Chiasmatypie. La Cellule, XXVII.

5. Metz, C. W. 1914. Chromosome Studies in the Diptera. I. Jour. Exper. Zool., XVIr.

6. Morgan, T. H. 1910. Sex-limited Inheritance in Drosophila. Science, XXXII.

7. Morgan, T. H. 1910. The Method of Inheritance of Two Sex-limited Characters in the Same Animal. Proc. Soc. Exp. Biol. Med., VIII.

8. Morgan, T. H. 1911. Random Segregation vs. Coupling in Mendelian Inheritance. Science, XXXIV.

9. Morgan, T. H. 1912. Complete Linkage in the Second Chromosome of the Male. Science, XXXVI.

10. Morgan, T. H., and Lynch, C. J. 1912. The Linkage of Two Factors in Drosophila, ete. Biol. Bull., XXIII.

11. Morgan, T. H., Sturtevant, A. H., Muller, H. J., and Bridges, C. B. The Mechanism of Mendelian Heredity. 1915. Henry Holt \& Co.

12 Muller, H. J. 1914. A Gene for the Fourth Chromosome of Drosophita. Jour. Exper. Zoool., XVII. Jour. Exper. Zool., V.

13. Stevens, N. M. 1909. A Study of the Germ Cells of Certain Diptera.

14. Sturtevant, A. H. 1913. The Linear Arrangement of Six Sex-linked Factors, as Shown by Their Mode of Association. Jour. Exper. Zool., XIV.

15. Sturtevant, A. H. 1913. A Third Group of Linked Factors in Drosophila. AM. NAT.

16. Sturtevant, A. H. 1915. The Behavior of the Chromosomes, as Studied through Linkage. Zeit. f. ind. Abst. u. Vererb.

17. Sturtevant, A. H. 1914. The Reduplication Hypothesis as Applied to Drosophila. AM. NAT., XLVIII.

18. Trow, A. H. 1913. Forms of Reduplication. Primary and secondary. Jour. Gen., II.

19. Wenrich, D. H. 1915. Synapses and the Individuality of the Chromosomes. Science, N. S., XLI. 